
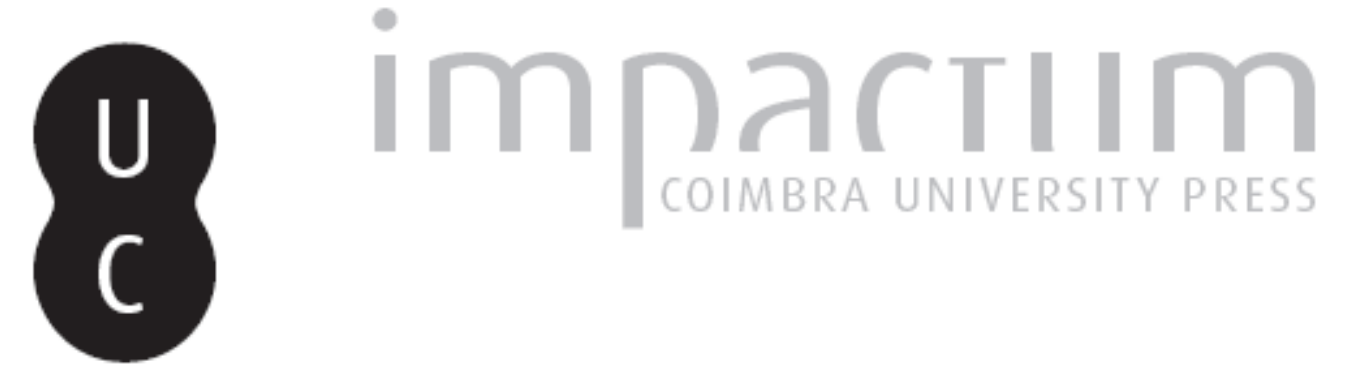

\title{
Direito natural e direito positivo em Kant e Fichte
}

Autor(es): $\quad$ Ugarte, Óscar Cubo
Publicado por: Faculdade de Letras da Universidade de Coimbra, Instituto de Estudos Filosóficos

URL persistente:

URI:http://hdl.handle.net/10316.2/29469

DOI:

DOI:http://dx.doi.org/10.14195/0872-0851_41_9

Accessed : $\quad$ 26-Apr-2023 10:25:51

A navegação consulta e descarregamento dos títulos inseridos nas Bibliotecas Digitais UC Digitalis, UC Pombalina e UC Impactum, pressupõem a aceitação plena e sem reservas dos Termos e Condições de Uso destas Bibliotecas Digitais, disponíveis em https://digitalis.uc.pt/pt-pt/termos.

Conforme exposto nos referidos Termos e Condições de Uso, o descarregamento de títulos de acesso restrito requer uma licença válida de autorização devendo o utilizador aceder ao(s) documento(s) a partir de um endereço de IP da instituição detentora da supramencionada licença.

Ao utilizador é apenas permitido o descarregamento para uso pessoal, pelo que o emprego do(s) título(s) descarregado(s) para outro fim, designadamente comercial, carece de autorização do respetivo autor ou editor da obra.

Na medida em que todas as obras da UC Digitalis se encontram protegidas pelo Código do Direito de Autor e Direitos Conexos e demais legislação aplicável, toda a cópia, parcial ou total, deste documento, nos casos em que é legalmente admitida, deverá conter ou fazer-se acompanhar por este aviso.

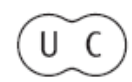




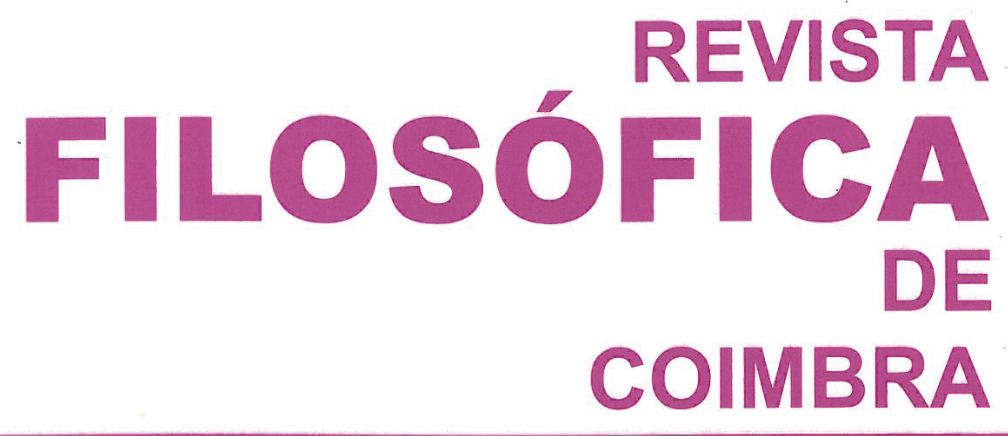

vol. 21 - número 41 - março 2012

vol. 21 - número 41 - março 2012

Fundação Eng. António de Almeida

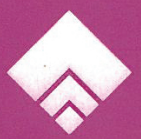




\section{DIREITO NATURAL E DIREITO POSITIVO EM KANT E FICHTE}

ÓSCAR CUBO UGARTE*

“O estado não tem o direito nem o poder de ordenar que os cidadãos devem confiar uns nos outros, posto que ele próprio está erigido sobre a desconfiança universal; e não deve fiar-se nem sequer em si mesmo." (Fichte. GA. I/4, 47).

Resumo: O presente trabalho analisa alguns pontos de contacto entre a filosofia do direito de Kant e de Fichte. Para o efeito, apresentamos a ideia de ambos sobre o direito natural como direito racional. Encontramos o ponto fundamental de união entre ambos na sua interpretação de direito natural como disciplina fundada no conceito da liberdade prática. Deste ponto de vista e a partir da diferença estabelecida por Kant na «Doutrina do Direito» da Metafísica dos Costumes entre direito natural e direito positivo analisamos o modo como ambos os autores defendem a ideia de um direito racional como modelo jurídico ao qual as ordens jurídicas positivas se têm que ater.

Palavras chave: Direito natural, direito racional, liberdade, reciprocidade, justiça.

Summary: This paper discusses some points of contact regarding the philosophy of law of Kant and Fichte. For this reason, we introduce the idea that both authors understand natural law as rational law. The fundamental point of union between these two authors resides in their interpretation of natural law as a discipline based on the concept of practical freedom. From this point of view, and from the distinction established by Kant's "Doctrine of Right" in the Metaphysics of Morals between natural law and positive law, we analyze how both authors defend the idea of a rational law as a legal model that has to be adjusted in the positive law order.

Keywords: Natural law, Rational law, Freedom, Reciprocity and Justice.

\footnotetext{
* Investigador da Alexander von Humboldt-Stiftung.
} 
Do ponto de vista da filosofia de direito, são numerosos os pontos de encontro entre Kant e Fichte. No presente artigo vamo-nos centrar no modo como ambos os autores defendem a ideia de um direito natural como direito racional. O que vincula estreitamente a filosofia jurídica de ambos os autores é que os dois entendem por direito natural uma disciplina racional fundada sobre o conceito de liberdade. A este respeito vamos analisar as correspondências entre estes dois autores a propósito de três questões. Em primeiro lugar, vamos apresentar a diferença que Kant estabelece, na "Doutrina do Direito" da Metafísica dos Costumes, entre direito natural e o direito positivo; em segundo lugar, vamos explorar a noção de "direito originário" que Fichte desenvolve no Fundamento do Direito Natural segundo os Princípios da Doutrina da Ciência; e, por fim, vamos apresentar o modo como ambos os autores defendem a ideia de um direito racional como um modelo transcendental a que se têm de ajustar as ordens jurídicas positivas.

\section{Direito positivo e direito racional em Kant}

Para entender que no pensamento de Kant a noção de direito natural está associada à ideia de liberdade, convém ter em conta o lugar que a filosofia do direito ocupa dentro da complexa arquitectura da filosofia crítica de Kant. As duas "Introduções" à Crítica do Juízo desempenham um papel fundamental nesta tarefa de contextualização, pois é nelas que Kant apresenta com maior clareza o sistema da sua filosofia. Este sistema tem duas grandes esferas (Gebiet): a esfera da natureza e a esfera da liberdade, sobre as quais se pode erigir uma dupla metafísica, a saber, uma "metafísica da natureza" no que respeita à filosofia teórica e uma "metafísica dos costumes" no que respeita à filosofia prática. Em contraste com a Crítica da Razão Prática que indaga o espaço ou o "padrão" normativo básico da moralidade, ${ }^{1}$ a mencionada Metafísica dos Costumes estuda não só as condições subjectivas de aplicação do princípio supremo da moralidade à natureza peculiar do homem ("Doutrina da Virtude"), mas também o princípio específico de que a razão pura se serve na sua legislação prático-jurídica ("Doutrina do Direito"). Ora bem, o tratamento kantiano do direito natural tem o seu lugar sistemático na mencionada "Doutrina do Direito" da Metafisica dos Costumes.

O conceito de direito natural na filosofia jurídica de Kant é sobretudo um conceito crítico-normativo que tem a sua origem nos ditames práticos da razão pura prática. Isto é, o pensamento jurídico de Kant parte do facto

${ }^{1}$ Veja-se a este respeito: J. M. Torralba 2009: 269-284. 
"de que existem princípios jurídicos supra-positivos que, por cima de toda a ordem jurídica vigente, constituem uma regra universalmente válida e absolutamente obrigatória". ${ }^{2} \mathrm{O}$ estudo destes princípios corresponde ao direito natural entendido como um direito fundado única e exclusivamente na razão. A ideia de um direito natural fundado na razão faz com que os princípios puros do direito não se baseiem em nenhum tipo de preconceito jurídico nem em nenhum livro jurídico estatutário de uma determinada época ou cultura. $\mathrm{O}$ estudo dos mencionados códigos jurídicos estatutários é o objecto de estudo da ciência do direito positivo. O objecto do direito positivo é sempre, por conseguinte, a legislação jurídica positiva de uma determinada época e cultura, ao passo que o objecto do direito natural são os mencionados princípios jurídicos supra-positivos, válidos universalmente para qualquer ser racional.

Em virtude desta regra jurídica suprema, toda a legislação jurídico-positiva tem que respeitar os princípios imutáveis da razão pura prático--jurídica. Ou seja, toda a lei positiva deve observar e respeitar os princípios imutáveis do direito. O axioma do direito natural segundo Kant é o seguinte: "age de tal modo que o uso livre do teu arbitrio possa coexistir com a liberdade de cada um segundo uma lei universal ". ${ }^{3}$ Este axioma oferece uma definição meta-positiva do direito, cuja validade não procede de nenhuma convenção ou consenso (que se supõe sempre empírico - salvo no caso do contrato original), nem se deixa derivar do conteúdo histórico-empírico das leis de um determinado povo ou nação. Ou seja, do ponto de vista da razão pura prático-jurídica "o direito é o conjunto das condições sobre as quais o arbitrio de um se pode conciliar com o arbitrio de outro segundo uma lei universal da liberdade". ${ }_{4}$

Ora bem, uma das principais funções do referido axioma do direito natural é a de proporcionar um "critério normativo" para determinar se uma lei positiva é ou não conforme ao mencionado princípio. Com efeito, uma lei é conforme ao principio transcendental do direito na medida em que se orienta e respeita a simetria e a reciprocidade do uso da liberdade

2 O. Höffe 2004: 108.

${ }^{3}$ MdS. Ak.-Ausg. VI, 231.

${ }^{4} M d S$. Ak.-Ausg. VI, 230. Kant oferece ainda uma outra definição do direito na $M d S$, que diz o seguinte: "a lei universal do direito [é]: age externamente de tal modo que o livre uso do teu arbitrio possa coexistir com a liberdade de cada um segundo uma lei universal" (MdS. Ak.-Ausg. VI, 231). Em Über den Gemeinspruch: Das mag in der Theorie richtig sein, taugt aber nicht für die Praxis encontramos também a seguinte definição do direito: "o direito é a limitação da liberdade de cada um sob a condição da sua concordância com a lei universal de todos, na medida em que esta concordância seja possivel segundo uma lei universal" (Gemeinspruch. Ak.-Ausg. VIII, 289-290). 
de cada um dos seus cidadãos, sem qualquer discriminação no que se refere à sua raça, sexo, confissão religiosa, etc. Ou, dito de outro modo, uma lei positiva é conforme ao direito quando não entra em contradição com o referido princípio imutável da razão pura prático-jurídica. Isto oferece um duplo ponto de vista para ajuizar as leis de um determinado sistema jurídico: por um lado, permite ajuizar se uma lei é legal num determinado código civil positivo e, por outro lado, se é legítima do ponto de vista da razão. Este último modo de julgar é o que faz do direito natural em Kant uma importante instância crítica para ajuizar da conformidade das leis do direito positivo com o referido princípio jurídico-transcendental da razão prática.

Há, assim, uma diferença irredutível entre o direito natural, que se baseia em princípios a priori da razão pura prático-jurídica, e o direito positivo (estatutário), que procede sempre da vontade fáctica de um legislador, independentemente de se tratar de um monarca ou dos representantes eleitos democraticamente pelo povo. Neste ultimo caso, aquele que cumpra o papel do soberano tem que governar e emitir leis que respeitem o mencionado princípio da razão pura prático-jurídica. Kant é muito claro sobre isso: "o direito natural no estado de uma constituição civil (isto é, o direito natural que se pode deduzir de princípios a priori para ela) não pode ser prejudicado pelas leis estatutárias desta última."5 Graças a esta distinção entre o direito natural e o direito positivo pode-se afirmar que nem toda a lei "decidida democraticamente é, só por isso, legitima", ${ }^{6}$ posto que o elemento último de legitimação não é o arbítrio humano, mas única e exclusivamente a razão.

Em definitivo, a distinção entre direito positivo e direito natural serve a Kant para defender as duas teses seguintes: em primeiro lugar, para defender que a justificação dos ordenamentos jurídicos em geral não pode ser levada a cabo por meio de reflexões jurídico-políticas, posto que unicamente a razão pode oferecer uma justificação racional ao direito; e, em segundo lugar, para defender a ideia de que todo o ordenamento jurídico positivo deve orientar-se pelos ditames da razão pura prático-jurídica. Kant expressa isto com grande clareza no Conflito das Faculdades, onde afirma que "a ideia de uma constituição que esteja de acordo com o direito natural dos homens, a saber, que aqueles que obedecem à lei devem ser também, ao mesmo tempo, na sua união, legisladores, está na base de todas as formas politicas, e a comunidade [das gemeine Wesen] que é pensada conforme esta ideia, por meros conceitos da razão pura, é denominada um ideal platónico (respublica noumenon), que não é uma

\footnotetext{
${ }^{5}$ MdS. Ak.-Ausg. VI, 256.

${ }^{6}$ C. Fernández, P. Fernández; L. Alegre 2007: 94.
} 
quimera vazia mas a norma eterna para qualquer instituição civil em geral e livre de toda a guerra".7

O direito natural, longe de ser uma vã quimera, constitui por conseguinte a norma eterna para qualquer constituição civil em geral. O princípio transcendental do direito natural não é algo vazio e indeterminado mas exclui, pela sua própria forma, todas aquelas constituições que contenham leis estatutárias contrárias ao direito natural. Exclui, por exemplo, toda a máxima jurídica que pretenda tratar desigualmente situações iguais, uma vez que é a própria forma da lei que impede, por princípio, essa desigualdade. Neste sentido, o "princípio transcendental do direito" fornece a condição mínima para que um ordenamento jurídico possa ajustar-se aos ditames da razão. ${ }^{8}$ Toda a legislação jurídica tem que respeitar o referido princípio, e só pode obter a sua legitimidade a partir da referida conformidade. A filosofia do direito de Kant permite pois um duplo juízo sobre as leis, quanto à sua legalidade e quanto à sua legitimidade.

O direito positivo, para ser justo, tem de se subordinar ao princípio transcendental do direito, ou seja, a sua legitimidade ou a sua justificação normativa não pode ser demonstrada senão por meio da própria razão. Isto é o que explica a "dupla linguagem jurídica" da "Doutrina do Direito" da Metafísica dos Costumes, visto que a legalidade de uma lei não implica a sua legitimidade e vice-versa. $\mathrm{O}$ direito natural como direito racional em Kant oferece, assim, um conceito bidimensional de "direito" em virtude do qual se pode e se tem de diferenciar entre a legalidade e a legitimidade das leis. Este carácter "normativo" do direito natural kantiano oferece pois uma valiosa instância crítica para ajuizar se uma ordem jurídica positiva satisfaz (ou não) as regras fundamentais do direito "justo" do ponto de vista da razão.

\section{Direito natural e direitos originários do homem em Fichte}

No caso de Fichte, o direito natural não significa tão-pouco um direito inato à "natureza" humana, mas um direito que brota e se funda na razão pura prática, ou seja, na liberdade. Também no caso de Fichte, o fundamento do direito natural é puramente racional e pode por isso ser objecto da reflexão filosófica a priori. Dito de outro modo, tão-pouco para Fichte o fundamento do direito natural é a natureza, mas a liberdade. No seu Fundamento Direito Natural segundo os Princípios da Doutrina da Ciência o autor é muito claro a esse respeito: "o conceito do direito

\footnotetext{
${ }^{7}$ Streit, Ak.-Ausg. VII 90-91.

${ }^{8}$ Veja-se a este respeito: M. Brocker 2006: 52.
} 
deve ser um conceito originário da razão pura". ${ }^{9} \mathrm{O}$ conceito do direito pertence, segundo Fichte à comunidade de seres livres e racionais onde "cada membro da sua sociedade aceita limitar a sua própria liberdade externa mediante a liberdade interior, de tal modo que também possam ser externamente livres todos os outros junto a ele". ${ }^{10}$ Só este princípio auto-limitativo torna viável uma comunidade de seres racionais e torna possível a fundação de um estado. De maneira análoga ao que acontece com Kant, e apesar das diferenças no que respeita ao carácter hipotético ou categórico do axioma fundamental do direito, Fichte se serve da ideia de uma auto-limitação recíproca como condição de possibilidade de toda a comunidade jurídica embora, em contraste com Kant, faça depender o surgimento da referida comunidade da vontade fáctica dos indivíduos de auto-restringir realmente a sua liberdade. ${ }^{11}$ Em qualquer caso, para ambos os pensadores um sistema jurídico racional é sempre um sistema estruturado internamente pelos princípios da simetria e da reciprocidade.

Ora bem, uma das ideias completamente originais de Fichte no Fundamento do Direito Natural é que ao homem enquanto ser livre e racional correspondem uma série de direitos originários ou "Urrechten». A primeira característica dos referidos direitos originários é que se trata de direitos inalienáveis, isto é, direitos a que não se pode renunciar sem renunciar ao mesmo tempo à própria liberdade. Estes direitos são ditados a partir da liberdade pela própria razão sem que seja possível a sua alienação. De um ponto de ponto jurídico, isto significa que os mencionados direitos originários do homem devem estar acolhidos em todas as constituições jurídico-políticas, para que estas obtenham uma forma realmente racional. Estes direitos originários têm um estatuto jurídico e ontológico distinto do das leis de ordem positiva que regem os estados, posto que estão acima de qualquer legislação jurídico-política e não são susceptíveis de ser adquiridos ou renunciados por meio de nenhum contrato, estando eles mesmos, aliás, na base de qualquer contrato possível. Ou seja, trata se de direitos inalienáveis, anteriores aos direitos que se possam adquirir num determinado sistema jurídico positivo. ${ }^{12} \mathrm{~A}$ ideia fundamental é, todavia, que nenhum destes sistemas pode lesar ou contradizer os mencionados direitos originários do homem.

De maneira análoga ao pensamento de Kant sobre o direito natural, Fichte considera que estes direitos não dependem do consenso efectivo nem do arbítrio dos homens, visto que têm a sua fonte na legislação trans-

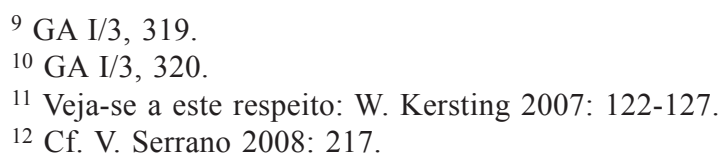


cendental de razão. É certo que estes direitos são caracterizados por Fichte no Fundamento do Direito Natural como ficções, ${ }^{13}$ ou como exigências formais da ciência do direito, mas como ficções que são indissociáveis do conceito de pessoa e da própria fundamentação do direito como aquilo que torna possível uma comunidade política entre seres racionais. $\mathrm{Ou}$ seja, os direitos originários constituem a súmula das condições sob as quais se pode garantir a liberdade das pessoas no contexto social, e são a chave para instituir uma comunidade jurídico-política onde as referidas condições sejam respeitadas. Neste sentido, remetem para as condições de possibilidade da fundação dos estados e dos direitos positivos vigentes nos mesmos.

A definição que Fichte dá dos direitos originários do homem é a seguinte: "o direito originário é o direito absoluto da pessoa a ser no mundo sensivel unicamente causa (e de não ser, por isso, nunca algo de causado [Bewirktes])". ${ }^{14}$ Uma pessoa é causa quando realiza ou pode realizar no mundo dos sentidos um determinado fim estabelecido por ela mesma, e isto é possível no referido mundo dos sentidos quando o seu corpo (como representante da sua personalidade no referido mundo) pode realizar fisicamente aquilo a que se propôs como fim. Ou seja, da ideia de um direito originário a ser sempre causa e nunca algo de causado no mundo dos sentidos se segue também o direito do corpo a agir e mover--se com liberdade para poder realizar os fins que toda a pessoa se propõe realizar. O corpo, como representante sensível da personalidade dos sujeitos racionais, tem direito à liberdade. Isto implica que diferentemente dos corpos naturais carentes de toda a personalidade moral, os corpos dos outros não podem ser um meio para a realização dos fins de outros, nem tão-pouco um objecto de consumo como os objectos da natureza em geral. Ou seja, os restantes corpos naturais (as coisas que a natureza oferece) podem ser possuídos e intercambiados num contexto social, mas o mesmo não sucede ao corpo próprio de cada cidadão, o qual pertence exclusivamente a cada um e é inviolável para os demais, os quais não têm qualquer direito a possuí-lo (nem sequer no matrimónio).

A novidade da filosofia do direito natural em Fichte é que introduz, na sua análise do direito originário, a determinação do corpo como elemento jurídico fundamental. Com efeito, cada pessoa tem o direito absoluto de ser unicamente causa neste mundo sensível mas, para que isso seja possível, a pessoa tem que poder determinar teleologicamente o seu corpo, de maneira que este tem de estar isento de qualquer entrave que o impeça de levar a cabo essa actividade teleológica. Este sentido positivo do direito

\footnotetext{
13 Veja-se a este respeito: GA I/3, 404.

14 GA I/3, 404.
} 
originário do corpo da pessoa a não ser impedido na sua livre mobilidade e causalidade também acarreta, de uma maneira negativa, a proibição igualmente originaria de não agir directamente sobre o corpo de outrem sem a prévia permissão deste. O direito originário envolve, assim, a este respeito: "1) o direito à manutenção da absoluta liberdade e inviolabilidade do corpo (ou seja, a que nenhuma acção seja exercida directamente sobre ele); e 2) o direito à manutenção da nossa livre influência em todo o mundo sensivel". ${ }^{15}$ No caso do homem, a violação do direito originário implica, consequentemente a violação da independência do seu corpo.

Ora, a este direito originário à liberdade do corpo pode também acrescentar-se, ainda que Fichte não o faça explicitamente, o direito de todo o ser racional a "poder viver do seu trabalho", ${ }^{16}$ já que disto depende a própria subsistência do corpo como representante da personalidade dos seres livres. Julgamos que este é o motivo por que Fichte entende o "direito de necessidade" de uma maneira diferente de Hegel nos Princípios da Filosofia do Direito, ao defender a ideia de que há um direito originário em virtude do qual todo aquele que não possa viver do seu trabalho e se encontre num estado de necessidade deve ser, por lei, ajudado pelos outros até que não mais se encontre no referido estado. Todos devem abrir mão de algo de seu para que ele possa viver. A partir do momento em que alguém sofra necessidade, diz Fichte, "aquela parte da propriedade de outrem que é requerida como contributo para o retirar da necessidade já não pertence a ninguém mas, por direito, àquele que sofre necessidade" ${ }^{17}$ Ou seja, todos os sistemas jurídico-políticos devem contemplar esta possibilidade e garantir com as suas leis a integridade do corpo dos seus cidadãos.

Em qualquer caso, o axioma do direito em Fichte, em virtude do qual "não posso renunciar à minha liberdade além do que é requerido para que os direitos dos outros com quem estou em comunidade no mundo sensivel possam subsistir com a minha liberdade", ${ }^{18}$ estrutura a esfera da liberdade dos corpos dos cidadãos e justifica por seu turno a legitimidade da coacção pública em defesa da própria integridade física dos cidadãos. Assim, justamente em virtude de que o corpo de uma pessoa é, do ponto de vista jurídico da razão, algo de absolutamente inviolável, o estado tem o direito de empregar a coacção e, por conseguinte, de restringir a liberdade do corpo daqueles cidadãos que tenham actuado arbitrária e ilegitimamente sobre o corpo dos demais. Por força dos referidos direitos originários do

\footnotetext{
$15 \mathrm{GA} \mathrm{I} / 3,409$.

16 GA I/4, 22.

${ }^{17}$ Ibidem.

$18 \mathrm{GA} \mathrm{I} / 3,396$.
} 
homem, compete pois ao estado salvaguardar a integridade corporal dos seus cidadãos, empregando para isso, se necessário for, métodos coercivos que limitam a liberdade corporal daqueles que não respeitam a simetria e a reciprocidade do direito à liberdade do corpo. Fichte é muito claro sobre isto: "atentar contra o corpo é violar, de uma só vez, todos os direitos do cidadão; é, consequentemente, um crime no estado, posto que o uso de todos os seus direitos está condicionado pela liberdade do seu corpo."19 O estado investigará sempre, por isso, a morte violenta dos seus cidadãos, visto que a sua morte e desaparição constituem um assunto público que diz respeito ao referido direito originário da liberdade do corpo.

\section{Da reforma progressiva do direito positivo em direcção a um direito racional}

Temos ainda de levantar e dar resposta a uma última questão relacionada com a possível colisão ou infracção dos ditames jurídicos da razão por parte do direito positivo e do seu sistema de leis. A reconversão por parte de Kant e de Fichte do direito natural num direito racional implica, conforme se viu, que o direito positivo tem como norma inquebrantável para a sua constituição os referidos princípios jurídicos da razão. No que toca ao Fundamento do Direito Natural de Fichte, isto significa que os direitos originários do homem têm de estar contemplados e protegidos dentro de todos os sistemas jurídicos positivos por meio de coacção. A coacção legítima dos poderes públicos do estado reside, pois, em que só ela permite a realização dos mencionados direitos no âmbito do mundo dos sentidos. Ou seja, Fichte entende a coacção pública como o meio indispensável para que cada corpo dos cidadãos possa viver e mover-se com segurança e liberdade por todo o território do estado. Neste sentido, para Fichte (do mesmo modo que para Kant), o estado não é uma invenção arbitrária, mas um mandato e uma exigência jurídica da razão. No que se refere à "Doutrina do Direito" de Kant, o estado, com o seu sistema jurídico de leis, tem igualmente a função legítima de coagir, sempre e em todos os casos em que a sua coacção esteja dirigida à preservação da esfera própria de liberdade de cada um dos seus cidadãos.

A dificuldade reside, porém, em que os referidos sistemas, bem como os seus respectivos estados, podem ser desconformes aos princípios jurídicos da razão. Surge, então, a pergunta sobre se se deve obedecer aos referidos códigos penais, mesmo quando sejam claramente desconformes aos ditames da razão, e violem os direitos originários dos homens.

${ }^{19} \mathrm{GA} \mathrm{I} / 4,48$. 
A resposta de ambos os autores é afirmativa, ou seja, deve-se obedecer às leis ainda que sejam desconformes aos ditames da razão. Fichte chega mesmo a falar dos "mártires do direito" 20 referindo-se àqueles que, por força de certos ideais de justiça, cometem actos ilegais; a sua valoração é clara: apesar das suas boas intenções, têm que ser penalmente castigados pela ilegalidade dos seus actos.

Nisto reside também para Kant o veto contra todo o direito à revolta tomando como padrão os critérios da justiça do direito racional. Um putativo direito a desobedecer às leis é impossível, porquanto é uma contradição jurídica, ${ }^{21}$ uma vez que se apela a um pretenso direito para ir além do próprio direito. Ou seja, deve-se obedecer incondicionalmente às leis de um determinado sistema jurídico, porque disto depende a conservação do próprio estado jurídico de uma nação determinada. A resistência contra as leis positivas é interdita, visto que isto reconduziria a sociedade a um "estado jurídico de natureza", 22 sendo uma obrigação da própria razão instaurar um estado regulado por leis jurídicas. Este é o motivo da denegação de todo o "direito" à rebelião na filosofia jurídica de Kant e de Fichte, que chega a qualificar a rebelião e a revolução como actos de alta traição contra o estado. ${ }^{23}$

No entanto, apesar da deslegitimização de toda a tentativa revolucionária, a defesa de um direito natural por parte de ambos os autores implica uma importante tarefa histórica, a saber, a tarefa de promover constantemente o progresso a partir de uma constituição não inteiramente justa em direcção a uma mais justa, posto que, em última instância, todos os sistemas jurídicos têm de seguir os ditames da razão. Ou seja, "a primeiríssima exigência é a de que de algum modo, e como for possivel, se escolha uma qualquer constituição legal [...]. De facto, a pior das constituições é melhor do que não ter nenhuma. Mas a partir deste momento deve-se pensar e trabalhar para a conduzir até à única constituição conforme à razão." 24 Neste ponto, a defesa de um direito natural como um direito racional oferece, por parte de ambos os autores, uma valiosa instância crítica para reflectir acerca dos ordenamentos jurídicos positivos sem que isto implique algum direito à desobediência e à rebelião.

\footnotetext{
20 Veja-se a este respeito: GA I/3, 458.

21 Veja-se a este respeito: W. Kersting 2007: 69.

22 Relig. Ak.-Ausg. VI, 95.

${ }^{23}$ Veja-se a este respeito: GA I/4, 66 y ss.

24 O. Faustino 2008: 184.
} 


\section{BIBLIOGRAFIA}

BROCKER, Manfred. Kant über Rechtstaat und Demokratie. VS Verlag für Sozialwissenschaften, Wiesbaden, 2006.

COLOMER MARTÍN-CALERO, José Luis. La teoría de la justicia de Immanuel Kant. Centro de Estudios Constitucionales, Madrid, 1995.

CONTRERAS PELÁEZ, Francisco J.. El tribunal de la razón. El pensamiento jurídico de Kant. Editorial Mad, Sevilla, 2005.

FERNÁNDEZ LIRIA, Carlos; Fernandez Liria, Pedro; Alegre Zahonero, Luís. Educación para la Ciudadanía. Akal, Madrid, 2007.

FICHTE, Johann Gottlieb. Gesamtausgabe der Bayerischen Akademie der Wissenschaften, Friedrich Frommann Verlag, Stuttgart-Bad Cannstatt, 1966.

HÖFFE, Otfried. Estudios sobre teoría del derecho y de la justicia. Distribuciones Fontamara, México, 2004.

HORSTMANN, Rolf-Peter. "Theorie des Urrechts (§§ 8-12)". In: Grundlage des Naturrechts. Merle, Jean-Christophe (Ed.), Akademie Verlag, Berlín, 2001.

KANT, Immanuel. Kant's gesammelte Schriften, hrsg. von der Preussichen und der Deutschen Akademie der Wissenschaften, Berlin, 1902 ss.

KERSTING, Wolfgang. Wohlgeordnete Freiheit. Immanuel Kants Rechts- und Staatsphilosophie. Mentis Verlag, Paderborn, 2007.

ONCINA, Faustino. "Derecho político y derecho a la política en el Fichte de Jena". In: Christophe Goddard, Jean; Rivera de Rosales, Jacinto (Eds.), Polimetrica, Italia, pp. 177-193, 2008.

SERRANO, Vicente. "Fichte y la compresión de los derechos humanos". In: Fichte et la politique. Christophe Goddard, Jean; Rivera de Rosales, Jacinto (Eds.), Polimetrica, Italia, pp. 211-223, 2008.

TORRALBA, José María. Libertad, objeto práctico y acción. La facultad del juicio en la filosofía moral de Kant, OLMS, Hildesheim, Zürich, New York, 2009.

VV.AA. Grundlage des Naturrechts. Merle, Jean-Christophe (Ed.), Akademie Verlag, Berlín, 2001.

VV.AA. Fichte et la politique. Christophe Goddard, Jean; Rivera de Rosales, Jacinto (Eds.), Polimetrica, Italia, 2008.

VV.AA. Metaphysische Anfangsgründe der Rechtslehre. Höffe, Otfried (Ed.), Akademie Verlag, Berlín, 2008. 